\title{
Erratum to: Efficacy of Angiotensin-Converting Enzyme Inhibitors and Angiotensin-Receptor Blockers in Coronary Artery Disease without Heart Failure in the Modern Statin Era: a Meta-Analysis of Randomized-Controlled Trials
}

\author{
Vu Hoang ${ }^{1}$ - Mahboob Alam ${ }^{1}$ - Daniel Addison ${ }^{1} \cdot$ Francisco Macedo $^{1} \cdot$ Salim Virani $^{2}$. \\ Yochai Birnbaum ${ }^{1}$
}

Published online: 12 March 2016

(C) Springer Science+Business Media New York 2016

Erratum to: Cardiovase Drugs Ther

DOI: 10.1007/s10557-016-6652-7

The original version of this paper was unfortunately published with incorrect authorgroup and incorrect affiliation. Michael E. DeBakey is part of an institutional affiliation but was inadvertently listed as one of the authors which should not be the case. Authorgroup and affiliation are now correct as shown in this erratum and in the current version.

The online version of the original article can be found at http://dx.doi.org/ $10.1007 / \mathrm{s} 10557-016-6652-7$

Vu Hoang

vlhoang@bcm.edu

Yochai Birnbaum

ybirnbaum@bcm.edu

1 Department of Internal Medicine, Division of Cardiology, Baylor College of Medicine, Faculty Center, One Baylor Plaza MS: BCM 620, Houston, TX 77030, USA

2 Michael E. DeBakey Veterans Affairs Medical Center Health Services Research and Development and Section of Cardiology, Department of Internal Medicine, Baylor College of Medicine, Houston, TX, USA 